N.0. 4763 February 11, 1961
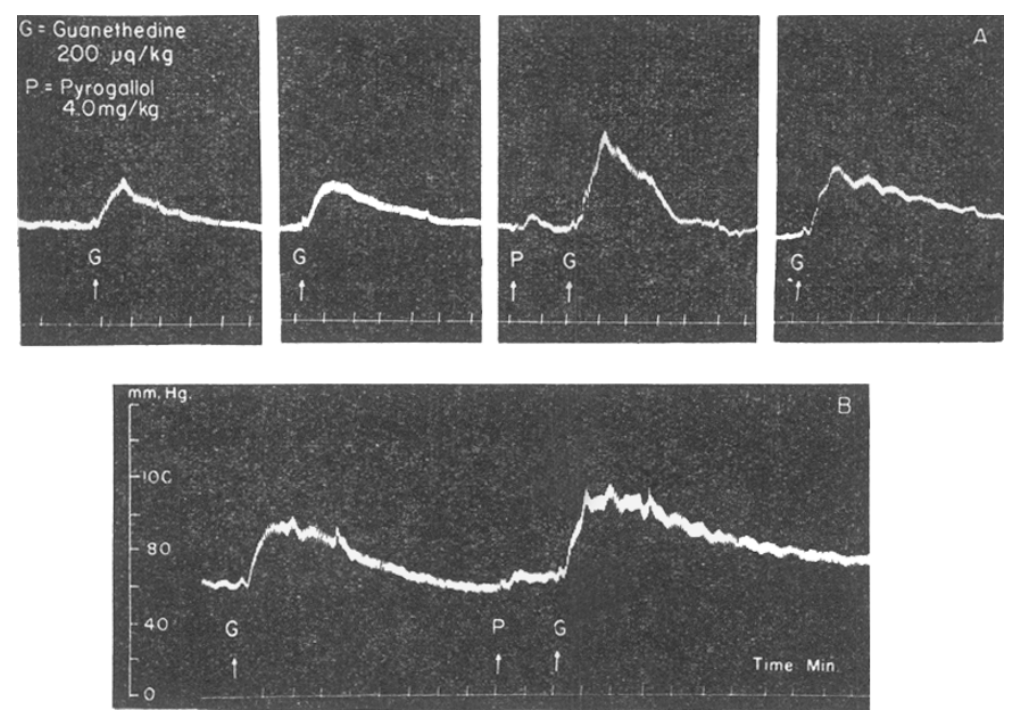

Fig. 1. Pressor responses to guanethedine $(G)$ and pyrogallol $(P)$ glus guanethedine, before and after bilateral adrenalectomy between tracings $\boldsymbol{A}$ and $\boldsymbol{B}$

The distribution of sweat glands has been studied in the dorsal and ventral skin and in hump, dewlap and navel flap. The secreting surface area of a single sweat gland is not significantly higher in the hump, but the effective secreting surface per sq. cm. of skin surface is much higher owing to a very high concentration of sweat glands 1 .

An attempt has been made to study the physiological function or the activity of the sweat glands by determining the evaporation of sweat from different cutaneous surfaces by Berman's method ${ }^{8}$. Cobalt chloride anhydride paper disks $(28.3$ sq. $\mathrm{mm}$.) were applied on different areas of the body and the time for the complete change of colour noted at an ambient temperature of $38^{\circ} \mathrm{C}$. and 74 per cent relative humidity. The average time taken for the dorsal trunk to decolorize the disks was $3 \mathrm{~min}$. 17 sec., and taking this as the standard 100 per cent evaporation, the

were similar to those before adrenalectomy and could still be augmented by pyrogallol. The tracing obtained during one of these experiments is shown in Fig. 1.

It would therefore appear from the results given here that guanethedine causes a pressor response by the indirect mochanism of releasing catecholamines as this response is augmented by prior administration of pyrogallol, a known catechol O-methyltransferase inhibitor. As the pressor response is not diminished by ganglionic blocking agents ${ }^{2}$ and is not much affected by bilateral adrenalectomy, it becomes more probable that guanethedine liberates catecholamines from the sympathetic nerve endings. Such a mechanism of action would explain the sympathetic atony reported by Maxwell et al. ${ }^{2}$ to follow several hours after medication.

I am grateful to Mrs. M. Hart for assistance.

$$
\text { D. W. WYuIE }
$$

Pharmacology Department,

Sterling-Winthrop Research Institute, Rensselaer, New York.

1 Page, I. H., and Dustan, H. P., J. Amer. Med. A8soc., 170, 1265 (1959).

${ }^{2}$ Maxwell, R. A., Plummer, A. J., Schneider, F., Povalski, H., and Daniel, A. I., J. Pharmacol." Exp. Therap., 128, 2 (1960).

'Axeirod, J., Seience, 126, 400 (1957).

- Wylie, D. W., Archer, S., and Arnold, A., Pharmaoologist, 1, 54 (1959).

'Archer, S., Arnold, A., Kullnig, R. K., and Wylie, D. W., Arch. Biochem. Biophys., 67, 153 (1960).

- Wylie, D. W., Archer, S., and Arnold, A., J. Pharmacol. Exp. Therap., 130, $239(1960)$.

\section{Rate of Evaporation from Different Regions of the Skin of Indian Zebu Cattle}

InDIan zebu cattle differ from the cattle of the temperate regions in having a marked hump and voluminous dowlap and navel flap. These structures are specially well developed in areas with very oppres. sive summer heat, and it has been suggested that these special structures may be related to the animal's greater thermoregulatory power. relative evaporation-rate from other areas was 149 per cent on the hump and 124 per cent on the neck; but the rate on the abdomen was only 72 per cent and on the dewlap and sheath was only 58 per cent. Thus the hump has developed special thermoregulatory significance in the tropical zebu cattle. These findings also confirm the work on the Brahman cattle $^{3}$.

We are indebted to I.C.A.R. for grants-in-aid to defray the expenses of the investigation and to Lieut.-Colonel J. M. Lahiri, director of veterinary services and animal husbandry, West Bengal, and to Principal K. C. Kukherjee for their interest and advice.

\section{Roy Chowdhury D. P. SADHU}

Department of Physiology and Nutrition, Bengal Veterinary College, Calcutta, 37.

${ }^{1}$ I.C.A.R. Animal Nutrition Comm. Rep. 1960.

${ }^{2}$ Berman, A., Nature, 179, 1256 (1957).

${ }^{3}$ Kibler, H. H., and Yeck, R. G., Univ, Missouri Agric. Exp. Ste. Res. Bull. 701 (1959).

\section{Inability of Refined Corn Oil to influence Spontaneous Arteriosclerosis of Old Hens}

According to a large number of reports, vegetable oils (such as corm, cotton-seed, rape-seed, safflower oil, etc.) are able to decrease serum cholesterol both in man and experimental animals. Some evidence exists that this effect is, at least partly, related to the presence of highly unsaturated fatty acids such as linoleic acid. It is not clear, however, whether such vegetable oils also have beneficial effects on arteriosclerotic lesions. After cholesterol-feeding, conflicting results have been reported with rabbits as well as with cockerels. Experimental arteriosclerosis due to cholesterol-feeding may, however, be different from arteriosclerosis in man. Probably the spontaneous arteriosclerotic lesions in old birds, for example hens ${ }^{\mathbf{1}}$, are more like human arteriosclerosis. 